\title{
Una universidad abierta al mundo y a su tiempo
}

\author{
Olga Elizabeth Hansberg Torres
}

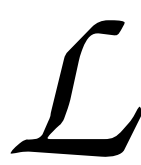

a adquisición de una lengua extranjera implica, más allá de la competencia lingüística de los sujetos, la apropiación de todo el orden cultural sobre el que descansa la tradición de un idioma y de sus habitantes.

Comprendida de esta manera, una segunda lengua tiene no sólo el carácter de vehículo de comunicación entre individuos de distintas nacionalidades, razas y culturas, o de herramienta complementaria para el trabajo profesional, académico, científico o intelectual; adquiere, además, la dimensión de un instrumento conceptual vasto mediante el cual los seres humanos tenemos la posibilidad de entender $y$ de valorar nuestro propio contexto, y lo que nosotros mismos somos a través del conocimiento de los otros.

Este fue, precisamente, el ideal que en 1921 animó la creación de la Escuela de Verano de la Universidad Nacional. De esa manera, mediante la enseñanza de nuestra lengua a estudiantes no hispanohablantes, nuestra institución erigía un espacio desde el que sería posible proyectar hacia el ámbito internacional la riqueza de la cultura mexicana en general, y de la Universidad en particular.

Convertida en el Centro de Enseñanza para Extranjeros, aquella escuela mantiene actualmente su importante misión académica, avalada por estudiantes e instituciones de todo el mundo.

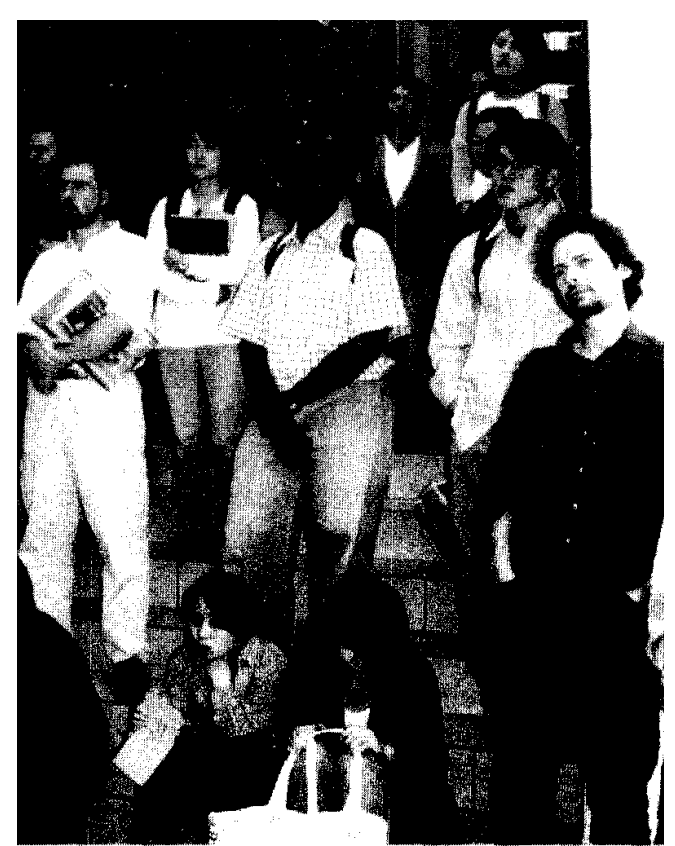

Distintas nacionalidades, razas y culturas

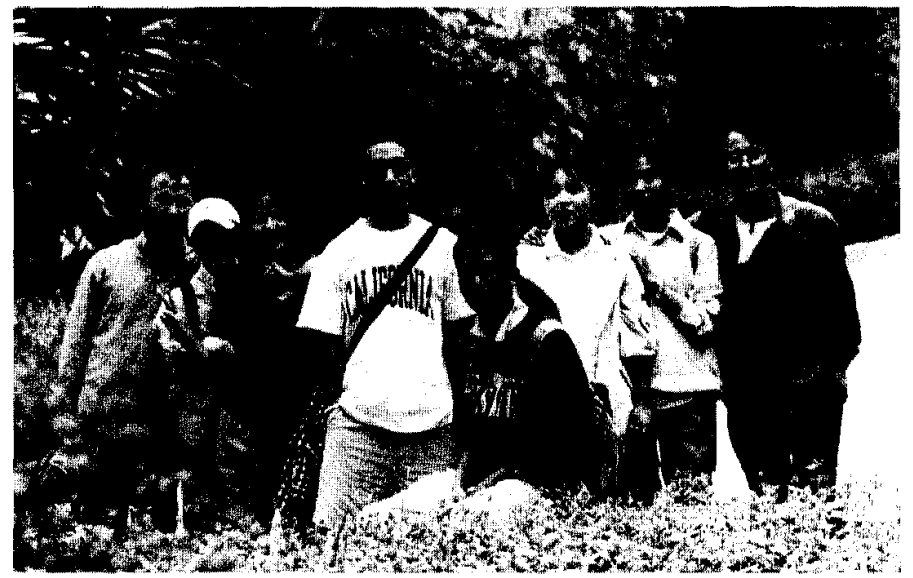

Alumnos del CEPE

* Coordinadora de Humanidades de la UNAM 
De manera cotidiana, desde cada una de sus sedes en México, Estados Unidos y Canadá, el CEPE refrenda el prestigio internacional obtenido a lo largo de ocho décadas. Es necesario reconocer, en este punto, el papel destacado que los profesores del Centro han tenido en el logro de dicho reconocimiento. Como oportunamente lo ha expresado su Director, gracias a sus maestros el CEPE ha logrado la madurez académica que lo ha convertido en líder de la enseñanza del español.

La celebración del octogésimo aniversario del Centro, en el marco de los festejos de los 450 años de la Universidad, es una ocasión ideal para hacer un recuento puntual de su pasado, pero también para reflexionar sobre la enorme responsabilidad que cada uno, como universitario, tiene en la definición de su futuro. $\mathrm{La}$ mesa redonda que a continuación se inaugura cumple con estos propósitos.

El aniversario me parece, pues, una ocasion propicia para recalcar que de la reflexión y de la discusión intensa $y$ madura de nuestras ideas, de los consensos y los acuerdos que los universitarios seamos capaces de tomar como comu-

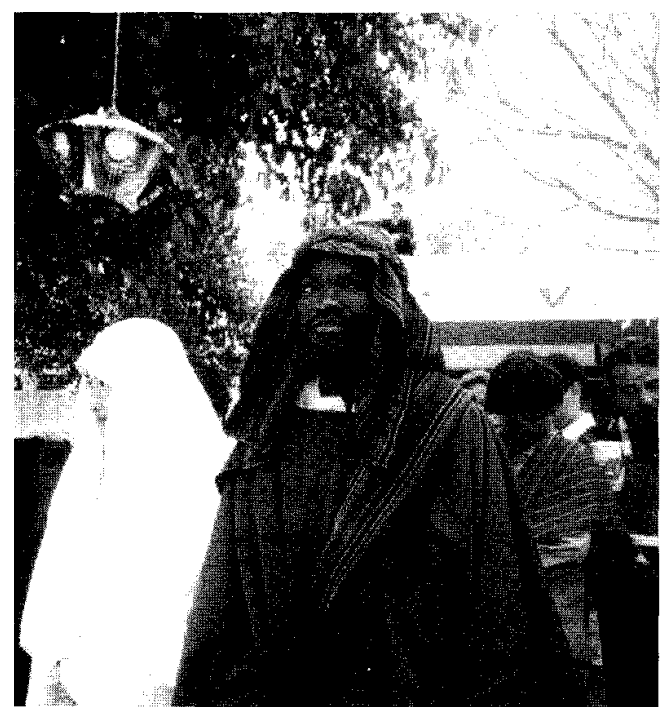

La INAM "abierta al mundo y a su tiempo"

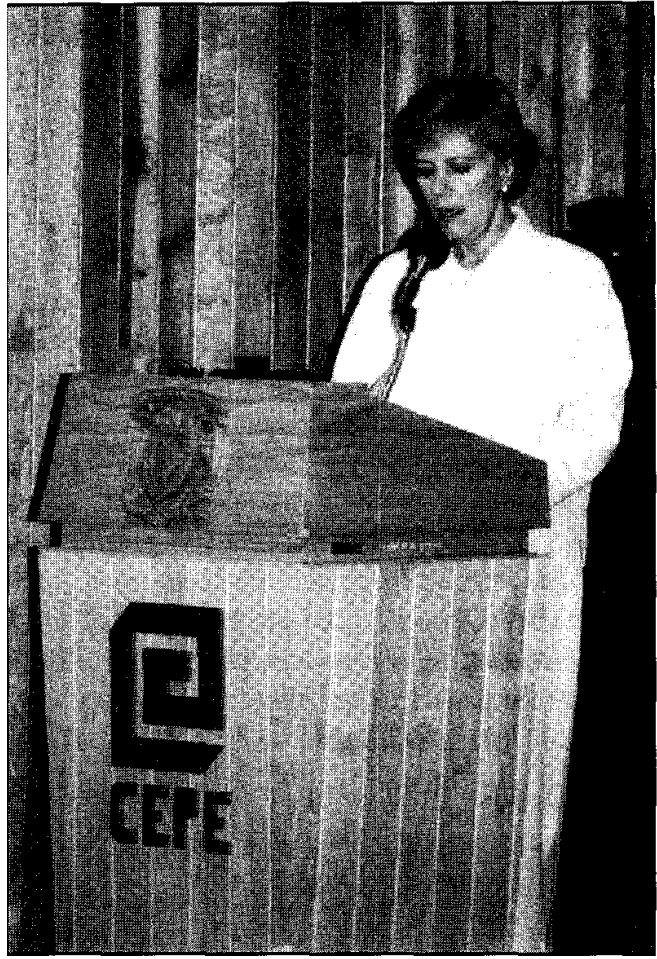

Olga Elizabeth Hansberg Torres

nidad, podrá surgir la institución que requieren los nuevos tiempos. Una Universidad Nacional fundada en su libertad $y$ en su autonomía, consolidada en lo académico, fortalecida en su misión cultural y en su carácter eminentemente humanístico y social. Una Universidad abierta al mundo $y$ a su tiempo.

Deseo felicitar a todos los que forman $y$ han formado parte de la comunidad del Centro de Enseñanza para Extranjeros de la UNAM durante estos primeros ochenta años de esfuerzo académico. Tengo la certeza de que continuarán trabajando, durante muchos años más, con el mismo compromiso, rigor y entusiasmo con que lo han hecho hasta ahora.

Hoy, 14 de septiembre de 2001, declaro formalmente inaugurada la mesa redonda: $A$ ochenta años de la Escuela de verano. Que continúen los éxitos 